\title{
Dietary supplementation with proline confers a positive effect in both porcine circovirus-infected pregnant and non-pregnant mice
}

\author{
Wenkai Ren ${ }^{1,2}$, Miaomiao Wu ${ }^{1,2}$, Wei Luo ${ }^{3}$, Ruilin Huang ${ }^{1}$, Yulong Yin ${ }^{1 *}$, Yinghui $\mathrm{Li}^{1,2}$, \\ Teijun $\mathrm{Li}^{1}$ and Xinglong $\mathrm{yu}^{3}$ \\ ${ }^{1}$ Observation and Experiment Station of Animal Nutrition and Feed Science in South-Central China, Ministry of Agriculture, \\ Hunan Provincial Engineering Research Center for Healthy Livestock and Poultry Production, Key Laboratory of \\ Agro-ecological Processes in Subtropical Region, Institute of Subtropical Agriculture, Chinese Academy of Sciences, \\ Changsha, Hunan 410125, People's Republic of China \\ ${ }^{2}$ Graduate University of the Chinese Academy of Sciences, Beijing 100039, People's Republic of China \\ ${ }^{3}$ College of Veterinarian Sciences, Hunan Agricultural University, Changsha, Hunan 410128, People's Republic of China
}

(Submitted 6 September 2012 - Final revision received 18 January 2013 - Accepted 30 January 2013 - First published online 18 March 2013)

\section{Abstract}

Porcine circovirus type 2 (PCV2) is associated with various diseases that impose a significant economic burden on the swine industry. We hypothesised that nutritional supplementation with proline to enhance the immune response might be a useful prophylactic measure against PCV2 infection. To test this hypothesis, in the present study, we measured clinical data, including blood parameters, serum cytokine profile, PCV2 virus load in organs and serum, and microscopic lesions in the lung, liver and spleen, in both PCV2-infected pregnant and non-pregnant mice. Dietary supplementation with proline had no effect $(P>0.05)$ on abortion rates in PCV2-infected pregnant mice, although a numerically lower abortion rate $(22 \cdot 2 v .44 .4 \%)$ was observed compared with the control. Dietary supplementation with proline significantly increased serum C-reactive protein levels $(P=0.03)$ in PCV2-infected pregnant mice, and increased serum TNF- $\alpha$ levels $(P=0.01)$, leucocytes $(P<0.05)$, lymphocytes $(P<0.05)$ and neutrophilic granulocytes $(P<0.05)$ in PCV2-infected non-pregnant mice. Meanwhile, dietary proline significantly $(P<0.05)$ decreased the PCV2 virus load in the lung. Furthermore, mice in the dietary proline group showed a significant $(P<0 \cdot 01)$ decrease in microscopic lesion scores in the lung, liver and spleen compared with those in the alanine group. Collectively, dietary proline supplementation confers a functional role in PCV2-infected mice.

Key words: Porcine circovirus type 2: Porcine circovirus-associated diseases: Proline: Nutritional regulations: Functional amino acids

Porcine circovirus type 2 (PCV2) is a circular, single-stranded DNA virus that was initially associated with a wasting disorder recognised as post-weaning multi-systemic wasting syndrome $^{(1,2)}$. However, later studies have indicated that PCV2 is also associated with porcine dermatitis and nephropathy syndrome, reproductive disorder, enteritis, proliferative and necrotising pneumonia and porcine respiratory disease complex, all of which are now called porcine circovirus-associated diseases or porcine circovirus diseases ${ }^{(3,4)}$. These diseases are usually characterised by progressive weight loss, a generalised enlargement of the lymph nodes, and pallor, jaundice and diarrhoea in some cases ${ }^{(5)}$. In addition to being highly pathogenic, it is found worldwide and therefore imposes a significant economic burden on the swine industry. Thus, many methods have been proposed to control PCV2 infection, such as containment and control, sound husbandry, herd management, good sanitation, immunisation and antibiotic therapy ${ }^{(6)}$. Unfortunately, many of these treatments are of limited use ${ }^{(7)}$. Therefore, nutritional regulation with functional amino acids to enhance the immune response might be useful as a prophylactic measure against PCV2 infection.

We previously found that dietary supplementation with arginine or glutamine enhanced the immune function in PCV2-infected mice, and may help eliminate PCV2 in experimentally infected mice ${ }^{(8-10)}$. We also found that dietary supplementation with arginine or glutamine partially reversed reproductive failure in mice caused by PCV2 infection ${ }^{(8-10)}$. As with arginine and glutamine, proline plays a versatile role in cell metabolism, physiology, intracellular redox status, oxidative stress and immune function ${ }^{(11-16)}$. Other reports have indicated that proline concentrations in porcine amniotic fluid increased by $141 \%$ between days 30 and 60 of gestation ${ }^{(17,18)}$.

Abbreviations: CRP, C-reactive protein; PCV2, porcine circovirus type 2. 
Similarly, concentrations of proline in ovine amniotic fluid increased from 89 to $172 \mu \mathrm{M}$, whereas concentrations in ovine allantoic fluid increased by $172 \%$ between days 30 and 60 of pregnancy ${ }^{(19)}$. These interesting results suggested that proline may play a vital role in fetal development. However, despite the versatile role of proline, there is little information available regarding the effect of proline on infection. Therefore, the aim of the present study was to determine the effect of dietary supplementation with proline in PCV2-infected pregnant and non-pregnant mice.

\section{Materials and methods}

\section{Preparation of porcine circovirus type 2 stock}

A PCV2 infectious clone constructed by self-ligation of the PCV2 genome via a SacII enzyme site was used to generate virus stock pools required for experimental infections. Briefly, the continuous porcine kidney cell line PK- $15^{(20)}$, free of PCV1 and PCV2, was cultured in Roswell Park Memorial Institute (RPMI)-1640 medium supplemented with 6\% (v/v) fetal calf serum. The cell monolayer was dispersed using trypsinEDTA and suspended in RPMI-1640 medium supplemented with $6 \%(\mathrm{v} / \mathrm{v})$ fetal calf serum. Cells were simultaneously infected with the PCV2 infectious clone. After $72 \mathrm{~h}$ of incubation, the infected cells were frozen and thawed three times, and the cell mixture was tested by PCR before being stored at $-20^{\circ} \mathrm{C}$. PCV2 stocks were titrated on PK-15 cells ${ }^{(20)}$.

\section{Experimental protocol}

Expt 1. The experiment was conducted as described previously with some modifications ${ }^{(12)}$. A total of forty female primiparous KM mice were obtained from the Laboratory Animal Center of Central South University, Hunan, China. The animals were housed in a pathogen-free mouse colony (temperature $20-30^{\circ} \mathrm{C}$, relative humidity $45-60 \%$ and lighting cycle $12 \mathrm{~h} / \mathrm{d}$ ) and had free access to food and drinking water. The animals were randomly assigned to a proline group (0.6\% proline + gestation diet, $n$ 20) or a control group (isonitrogenous $0 \cdot 46 \%$ alanine + gestation diet, $n$ 20). The amino acid content in the gestation diet was measured using the methods of Yin et al. ${ }^{(21)}$. Mice started to mate after $3 \mathrm{~d}$ of accommodation. An observable pessus was considered to be a prerequisite for judging copulation. Upon successful copulation, mice were fed diets supplemented with proline or alanine. Overall, nine mice in each group mated successfully. All mice were infected with PCV2 (2000 TCID50) on the 10th day after pregnancy, and the abortion rate was recorded in each group. Blood, serum, organs and the fetus were collected from female mice on the day of delivery for further analysis. A routine blood examination was performed at Huangxing Hospital, Changsha, China. Serum levels of IL-1 $\beta$, IL-6, TNF- $\alpha$ and C-reactive protein (CRP) were measured using ELISA kits in accordance with the manufacturer's instructions (Cusabio Biotech Company, Limited). The PCV2 virus load in the serum, lung, spleen and fetus was determined using quantitative PCR. Finally, microscopic lesions in the lung, liver and spleen were evaluated in a blinded fashion by a veterinary pathologist.

Expt 2. A total of twenty female KM mice (body weight 18-22 g) were obtained from the Laboratory Animal Center of Central South University, Hunan, China. The animals were housed in a pathogen-free mouse colony (temperature $20-30^{\circ} \mathrm{C}$, relative humidity $45-60 \%$ and lighting cycle $12 \mathrm{~h} / \mathrm{d}$ ) and had free access to food and drinking water. The animals were randomly assigned to a proline group ( $0.6 \%$ proline + gestation diet, $n$ 10) or a control group (isonitrogenous $0.46 \%$ alanine + gestation diet, $n$ 10). After $3 \mathrm{~d}$ of accommodation, all mice were infected with PCV2 (2000 TCID50) and fed a diet that was supplemented with either proline or alanine. At $7 \mathrm{~d}$ post-infection, all mice were killed to collect blood, serum and organs for further analysis. Blood parameters, serum cytokine profile, PCV2 virus load in the serum, lung and spleen, and microscopic lesions in the lung, liver and spleen were collected as in Expt 1.

All animal experiments were performed according to the guidelines of the Laboratory Animal Ethical Commission of the Chinese Academy of Sciences.

\section{DNA extraction and porcine circovirus type 2 quantitative $P C R$}

DNA was extracted from samples (spleen ( $5 \mathrm{mg}$ ), lung (10 mg), fetus $(10 \mathrm{mg})$ and serum $(100 \mu \mathrm{l}))$ using Tissue Genomic DNA Extraction Kits (Fisher). DNA from the samples was eluted with $80 \mu \mathrm{l}$ of elution buffer and stored at $-20^{\circ} \mathrm{C}$ for further use. DNA extracts were used for the quantification of PCV2 genomes by real-time PCR. Before the quantification of PCV2 genomes in the collected samples, a PCV2 real-time PCR standard was established. Briefly, a PCV2 genome was cloned in the $\mathrm{pMD}{ }^{\circledR} 18$ - $\mathrm{T}$ vector (TaKaRa) after PCR amplification with the following primers: forward 5'-CCGCGGGCTGGCTGAACTTTTGAAAG- $3^{\prime}$ and reverse $5^{\prime}$-CCGCGGAAATTTCTGACAAACGTTAC-3' (GenBank accession no. EU095020), and transformed in TOP10-competent cells (Invitrogen). The plasmid was prepared using a PureLinkTM HiPure Plasmid Midiprep Kit (Invitrogen). PCV2 plasmid was mixed with mouse DNA extracted from a PCV2 PCR-negative blood sample. For PCV2 quantification, 10-fold dilutions of this mixture (from $10^{11}$ to $10^{2}$ PCV2 copy numbers/ $\mu$ l) were used as a

Table 1. Effects of dietary supplementation with proline on serum cytokine profile in porcine circovirus type 2-infected pregnant mice*

(Mean values with their standard errors)

\begin{tabular}{lrrrrrr}
\hline & \multicolumn{2}{c}{$0.6 \%$ Pro } & & \multicolumn{2}{c}{$0.46 \%$ Ala } & \\
\cline { 2 - 3 } Catalogues & \multicolumn{1}{c}{ Mean } & SEM & & Mean & SEM & \\
\hline IL-1 $\beta(\mathrm{ng} / \mathrm{ml})$ & 48.32 & 1.86 & & 45.16 & 2.23 & 0.20 \\
IL-6 $(\mathrm{pg} / \mathrm{ml})$ & 220.81 & 51.87 & & 311.39 & 77.89 & 0.37 \\
TNF- $\alpha(\mathrm{ng} / \mathrm{ml})$ & 0.90 & 0.14 & & 1.17 & 0.13 & 0.23 \\
CRP $(\mu \mathrm{g} / \mathrm{ml})$ & 69.45 & 8.00 & & 49.81 & 1.88 & 0.03 \\
\hline
\end{tabular}

Pro, mice fed with a normal gestation diet with $0.6 \%$ proline supplementation; Ala, mice fed with a normal gestation diet with $0.46 \%$ alanine supplementation, as the isonitrogenous control; CRP, C-reactive protein.

${ }^{*}$ Five mice from the Pro group and six mice from the Ala group were used for serum cytokine analysis. 
Table 2. Effects of dietary supplementation with proline on serum cytokine profile in porcine circovirus type 2-infected non-pregnant mice* (Mean values with their standard errors)

\begin{tabular}{|c|c|c|c|c|c|}
\hline \multirow[b]{2}{*}{ Catalogues } & \multicolumn{2}{|c|}{$0.6 \%$ Pro } & \multicolumn{2}{|c|}{$0.46 \%$ Ala } & \multirow[b]{2}{*}{$P$} \\
\hline & Mean & SEM & Mean & SEM & \\
\hline IL-1 $\beta$ (ng/ml) & 39.25 & 5.93 & 49.82 & $5 \cdot 34$ & 0.19 \\
\hline IL-6 (pg/ml) & $522 \cdot 51$ & 7.63 & 548.03 & 29.00 & 0.44 \\
\hline TNF- $\alpha$ (ng/ml) & $1 \cdot 28$ & 0.32 & 0.63 & 0.11 & 0.01 \\
\hline CRP $(\mu \mathrm{g} / \mathrm{ml})$ & 51.91 & 8.05 & $50 \cdot 38$ & 2.73 & 0.86 \\
\hline
\end{tabular}

Pro, mice fed with a normal gestation diet with $0.6 \%$ proline supplementation; Ala, mice fed with a normal gestation diet with $0.46 \%$ alanine supplementation, as the isonitrogenous control; CRP, C-reactive protein.

* Six mice from the Pro group and six mice from the Ala group were used for serum cytokine analysis.

standard. PCR was performed using a SYBR Green detection kit (TaKaRa), containing $\mathrm{MgCl}_{2}$, deoxyribonucleotide triphosphate and Hotstar Taq polymerase. Then, $1 \mu$ l of template solution was added to a total volume of $10 \mu$ l containing a $5 \mu \mathrm{l}$ SYBR Green mix, and $0 \cdot 2 \mu \mathrm{l}$ each of the forward and reverse primers $(10 \mu \mathrm{M})$. We used the following protocol: (1) predenaturation $\left(30 \mathrm{~s}\right.$ at $\left.95^{\circ} \mathrm{C}\right)$; (2) amplification and quantification, repeated forty cycles $\left(5 \mathrm{~s}\right.$ at $95^{\circ} \mathrm{C}, 34 \mathrm{~s}$ at $\left.60^{\circ} \mathrm{C}\right) ;(3)$ melting $\left(60-99^{\circ} \mathrm{C}\right.$ at a heating rate of $0 \cdot 1^{\circ} \mathrm{C} / \mathrm{s}$ and fluorescence measurement)

\section{Histopathology}

Tissue samples of the spleen, liver and lung from mice that exhibited macroscopic lesions were fixed in $10 \%$ neutral buffered formalin, embedded in paraffin, sectioned ( $5 \mathrm{~mm}$ thick) and stained with haematoxylin and eosin for histopathological examination. Microscopic lesions were evaluated in a blinded fashion by a veterinary pathologist using a previously described scoring system ${ }^{(22)}$. Lung sections were examined for the presence and severity of interstitial pneumonia, and scored on a scale from 0 (normal) to 6 (severe diffuse). Sections of the liver were evaluated for the presence of lymphohistiocytic inflammation, and scored on a scale from 0 (none) to 3 (severe). The spleen was evaluated for the presence of lymphoid depletion and histiocytic inflammation, and scored on a scale from 0 (normal) to 3 (severe).

\section{Statistical analysis}

All statistical analyses were performed using SPSS 16.0 software. Group comparisons were performed using Student's $t$ test. Data on the abortion rates of pregnant mice and the detection rates of PCV2 virus in samples were analysed by $\chi^{2}$ analysis. Differences were considered as significant at $P<0.05$. Data are expressed as means with their standard errors of the mean.

\section{Results}

\section{Clinical observation}

As observed in our previous study, abortion occurred in late pregnancy. Overall, the abortion rates in the control and proline groups were $44.44 \%(n$ 4/9) and 22.22\% ( $n$ 2/9), respectively. However, dietary supplementation with proline had no effect $(P>0.05)$ on abortion rates in PCV2-infected pregnant mice, although a numerically lower abortion rate was observed compared with the control. Meanwhile, there was no difference in litter size between the proline and control groups (10.5 (SEM 0.43) v. 10.8 (SEM 0.73)).

\section{Cytokine profile and blood examination}

As shown in Table 1, dietary supplementation with proline significantly $(P=0.03)$ increased the serum CRP level, whereas there were no differences $(P>0.05)$ in serum IL-1 $\beta$, IL-6 and TNF- $\alpha$ levels in PCV2-infected pregnant mice. In PCV2infected non-pregnant mice, the serum TNF- $\alpha$ level in the proline group was significantly $(P=0 \cdot 01)$ higher than that in the control alanine group (Table 2). In the pregnant mouse model, there were no significant differences in serum IL-1 $\beta$, IL-6 and CRP levels between the proline and control alanine groups (Table 2). Furthermore, in PCV2-infected pregnant mice, no important difference in blood parameters was found between the proline and control groups (Table 3). In contrast, in PCV2-infected non-pregnant mice, dietary supplementation with proline significantly $(P<0.05)$ increased leucocytes, lymphocytes and neutrophilic granulocytes, compared with dietary supplementation with alanine (Table 4).

\section{Porcine circovirus type 2 virus load and microscopic lesions}

As shown in Table 5, in PCV2-infected pregnant mice, PCV2 DNA was detected in serum ( $n 3 / 6$ ), lung ( $n$ 5/6), fetus $(n 0 / 6)$ and spleen $(n 4 / 6)$ in the alanine group, whereas it was detected in serum $(n 4 / 6)$ in the proline group. In the

Table 3. Results of a routine blood examination in porcine circovirus type 2-infected pregnant mice $(n 6)$

(Mean values with their standard errors)

\begin{tabular}{|c|c|c|c|c|}
\hline \multirow[b]{2}{*}{ Catalogues } & \multicolumn{2}{|c|}{ Pro group } & \multicolumn{2}{|c|}{ Ala group } \\
\hline & Mean & SEM & Mean & SEM \\
\hline Leucocytes (×10/litre) & 6.44 & 0.77 & $6 \cdot 78$ & 0.78 \\
\hline $\mathrm{L}\left(\times 10^{9} /\right.$ litre $)$ & $5 \cdot 44$ & 1.71 & $5 \cdot 24$ & 0.66 \\
\hline MID (×109/litre) & 0.24 & 0.05 & 0.38 & 0.08 \\
\hline $\mathrm{N}\left(\times 10^{9} /\right.$ litre $)$ & 0.78 & 0.12 & 1.35 & 0.13 \\
\hline Erythrocytes (×10 $12 /$ litre) & $8 \cdot 75$ & 0.42 & $8 \cdot 50$ & 0.19 \\
\hline $\mathrm{Hb}(g / l)$ & $134 \cdot 00$ & 5.44 & $128 \cdot 80$ & 4.40 \\
\hline $\mathrm{HCT}$ & 0.38 & 0.01 & 0.36 & 0.01 \\
\hline MCV (fl) & $43 \cdot 20$ & 0.58 & $42 \cdot 20$ & 0.92 \\
\hline $\mathrm{MCH}(\mathrm{pg})$ & $15 \cdot 34$ & 0.21 & $15 \cdot 16$ & 0.37 \\
\hline $\mathrm{MCHC}(\mathrm{g} / \mathrm{l})$ & $355 \cdot 20$ & 1.53 & $359 \cdot 20$ & 1.02 \\
\hline RDW (\%) & $16 \cdot 68$ & 0.34 & $16 \cdot 80$ & 0.62 \\
\hline PLT $\left(\times 10^{9} /\right.$ litre $)$ & $500 \cdot 85^{\star}$ & 73.65 & $709 \cdot 40$ & $65 \cdot 75$ \\
\hline MPV (fl) & $6 \cdot 26$ & 0.23 & 5.80 & 0.30 \\
\hline PCT & 0.30 & 0.04 & 0.41 & 0.06 \\
\hline PDW & 43.56 & $6 \cdot 45$ & 32.78 & $3 \cdot 27$ \\
\hline
\end{tabular}

Pro, mice fed with a normal gestation diet with $0.6 \%$ proline supplementation; Ala, mice fed with a normal gestation diet with $0.46 \%$ alanine supplementation, as the isonitrogenous control; L, lymphocytes; MID, intermediate cell; N, neutrophilic granulocyte; HCT, haematocrit; MCV, mean corpuscular volume; $\mathrm{MCH}$, mean corpuscular $\mathrm{Hb}, \mathrm{MCHC}$, mean corpuscular $\mathrm{Hb}$ concentration; RDW, red cell distribution width; PLT, platelet; MPV, mean platelet volume; PCT, thrombocytocrit; PDW, platelet distribution width.

* Mean value was significantly different with respect to the control group $(P<0.05)$. 
Table 4. Results of a routine blood examination in porcine circovirus type 2-infected non-pregnant mice

(Mean values with their standard errors)

\begin{tabular}{|c|c|c|c|c|}
\hline \multirow[b]{2}{*}{ Catalogues } & \multicolumn{2}{|c|}{ Pro group } & \multicolumn{2}{|c|}{ Ala group } \\
\hline & Mean & SEM & Mean & SEM \\
\hline Leucocytes (×109/litre) & $8 \cdot 77^{*}$ & 1.09 & 6.03 & 0.67 \\
\hline $\mathrm{L}\left(\times 10^{9} /\right.$ litre $)$ & $7 \cdot 14^{*}$ & 0.74 & 4.65 & 0.60 \\
\hline MID $\left(\times 10^{9} /\right.$ litre $)$ & 0.60 & 0.16 & 0.28 & 0.07 \\
\hline $\mathrm{N}\left(\times 10^{9} /\right.$ litre $)$ & $1.67^{*}$ & 0.22 & 1.05 & 0.19 \\
\hline Erythrocytes ( $\times 10^{12} /$ litre) & $7.53^{\star}$ & 0.37 & 8.87 & 0.36 \\
\hline $\mathrm{Hb}(\mathrm{g} / \mathrm{l})$ & $117 \cdot 00$ & 3.65 & 130.50 & 6.54 \\
\hline $\mathrm{HCT}$ & 0.31 & 0.01 & 0.35 & 0.02 \\
\hline MCV (fl) & $41 \cdot 17$ & 0.31 & $40 \cdot 17$ & 1.30 \\
\hline $\mathrm{MCH}(\mathrm{pg})$ & $15 \cdot 12$ & 0.12 & $15 \cdot 06$ & 0.54 \\
\hline $\mathrm{MCHC}(\mathrm{g} / \mathrm{l})$ & $367 \cdot 83$ & 3.95 & $377 \cdot 00$ & 2.59 \\
\hline RDW (\%) & 16.75 & 0.36 & $17 \cdot 22$ & 0.67 \\
\hline PLT $\left(\times 10^{9} /\right.$ litre $)$ & $708 \cdot 20$ & $73 \cdot 10$ & $803 \cdot 83$ & 48.54 \\
\hline MPV (fl) & $6 \cdot 18$ & 0.28 & 6.42 & 0.65 \\
\hline PCT & 0.39 & 0.04 & 0.54 & 0.07 \\
\hline PDW & 39.83 & 2.99 & $32 \cdot 83$ & 3.62 \\
\hline
\end{tabular}

Pro, mice fed with a normal gestation diet with $0.6 \%$ proline supplementation; Ala mice fed with a normal gestation diet with $0.46 \%$ alanine supplementation, as the isonitrogenous control; L, lymphocytes; MID, intermediate cell; N, neutrophilic granulocyte; HCT, haematocrit; MCV, mean corpuscular volume; $\mathrm{MCH}$, mean corpuscular $\mathrm{Hb}$; $\mathrm{MCHC}$, mean corpuscular Hb concentration; RDW, red cell distribution width; PLT, platelet; MPV, mean platelet volume; PCT, thrombocytocrit; PDW, platelet distribution width.

* Mean values were significantly different with respect to the control group $(P<0.05)$.

alanine group, the mean PCV2 $\log _{10}$ genomic copies per $\mathrm{ml}$ (and/or per g) was 6.36 (SEM 1.42) for the spleen, 8.14 (sEM 1.89) for the lung and 3.72 (SEM 0.25 ) for the serum, whereas in the proline group, this was 3.21 (SEM 0.28) for the serum. Meanwhile, in the lung, the PCV2 virus detection rate in the alanine group was significantly $(P=0.015)$ higher than that in the proline group, whereas no difference was found for the other organisms. Similarly, as shown in Table 6, in PCV2-infected non-pregnant mice, PCV2 DNA was detected in serum $(n 1 / 6)$ and lung $(n 3 / 6)$ in the alanine group, but found only in serum $(n 1 / 6)$ in the proline group, and the mean PCV2 $\log _{10}$ genomic copies per $\mathrm{ml}$ (and/or per g) was 3.39 (SEM 0.05) for the lung and 3.27 for the serum in the alanine group, while in the proline group, this was 3.62 for the serum. No difference was found for the PCV2 virus detection rates between the alanine and proline groups.

As observed in previous reports and observations, PCV2 infection was associated with interstitial pneumonia and alveolar wall thickening due to macrophages and lymphocytes in the lung, lymphohistiocytic inflammation in the liver, and lymphoid depletion and histiocytic inflammation in the spleen ${ }^{(6,22,23)}$. In both PCV2-infected pregnant and non-pregnant mice, the lesions in the lung in the proline group (Fig. 1(a)) were not as severe as those in the control group (Fig. 1(b)). The proline group (Fig. 1(c)) showed less lymphohistiocytic inflammation in the liver than the alanine group (Fig. 1(d)). Furthermore, dietary supplementation with proline significantly decreased microscopic lesions in the spleen (Fig. 1(e) $v$. (f)). The microscopic lesion scores in the examined tissue samples are shown in Table 7. Mice in the dietary proline group showed a significant decrease in microscopic lesion scores in the lung, liver and spleen compared with those in the alanine group $(P<0 \cdot 01)$, although the difference in the lung was not statistically significant in non-pregnant mice $(P=0 \cdot 072)$.

\section{Discussion}

Among the numerous prophylactic measures that are currently available, nutritional regulation offers several advantages. The most compelling advantage is that it can increase resistance to a group of pathogens or even all pathogens, and thus can significantly reduce the incidence of diseases and the shedding of pathogens. Similar to other functional amino acids, proline plays an important role in cellular redox, cell proliferation, immunity and other physiological phenomena ${ }^{(13,14,18)}$. Unfortunately, there is currently a belief that proline is not especially necessary for gestating, neonatal, growing, infected or sick animals ${ }^{(24)}$. This unfavourable opinion reflects a lack of knowledge regarding the role of proline in immune regulation in infectious and morbid mammals. Thus, the present study was performed to examine the role of dietary supplementation with proline in PCV2-infected pregnant and non-pregnant mice. The dose of proline used in dietary supplementation was selected according to our previous study (WK Ren et al., unpublished results) and many Chinese reports. Pregnant and non-pregnant mouse models were chosen to perfect our experimental protocol and to enhance the creditability of the present experimental results.

PCV2 has been associated with many disease syndromes in pigs including swine reproductive failure, since it can replicate in embryos, lead to embryonic death and be passed through vertical transmission ${ }^{(25,26)}$. Similarly, a significant abortion rate was observed in pregnant mice after PCV2 infection at $0-14 \mathrm{~d}$ of gestation ${ }^{(10)}$. In the present study, dietary supplementation with proline had no effect on abortion rates in

Table 5. Porcine circovirus type 2 (PCV2) virus load in the serum, fetus, spleen and lung of PCV2-infected pregnant mice†

(Mean values with their standard errors)

\begin{tabular}{|c|c|c|c|c|c|c|c|c|c|c|c|c|}
\hline \multirow[b]{2}{*}{ Groups } & \multicolumn{3}{|c|}{ Serum } & \multicolumn{3}{|c|}{ Lung } & \multicolumn{3}{|c|}{ Spleen } & \multicolumn{3}{|c|}{ Fetus } \\
\hline & $n$ & Mean & SEM & $n$ & Mean & SEM & $n$ & Mean & SEM & $n$ & Mean & SEM \\
\hline $0.6 \%$ Pro & $4 / 6$ & $3 \cdot 21$ & 0.28 & $0 / 6$ & 0.00 & 0.00 & $0 / 6$ & 0.00 & 0.00 & $0 / 6$ & 0.00 & 0.00 \\
\hline $0.46 \%$ Ala & $3 / 6$ & $3 \cdot 72$ & 0.25 & $5 / 6$ & $8 \cdot 14^{\star \star}$ & 1.89 & $4 / 6$ & $6 \cdot 36^{\star \star}$ & 1.42 & $0 / 6$ & 0.00 & 0.00 \\
\hline
\end{tabular}

Pro, mice fed with a normal gestation diet with $0.6 \%$ proline supplementation; Ala, mice fed with a normal gestation diet with $0.46 \%$ alanine supplementation, as the isonitrogenous control.

** Mean values were significantly different with respect to the proline group $(P<0.01)$.

†Five mice from the Pro group and six mice from the Ala group were used for PCV2 virus load analysis. The detection rate is shown as number of positive mice/number of tested mice. The PCV2 load is shown as mean PCV2 $\log _{10}$ genomic copies per ml (and/or per g). 
Table 6. Porcine circovirus type 2 (PCV2) virus load in the serum, spleen and lung of PCV2-infected non-pregnant mice† (Mean values with their standard errors)

\begin{tabular}{|c|c|c|c|c|c|c|c|c|c|}
\hline \multirow[b]{2}{*}{ Groups } & \multicolumn{3}{|c|}{ Serum } & \multicolumn{3}{|c|}{ Lung } & \multicolumn{3}{|c|}{ Spleen } \\
\hline & $n$ & Mean & SEM & $n$ & Mean & SEM & $n$ & Mean & SEM \\
\hline $0.6 \%$ Pro & $1 / 6$ & 3.62 & 0.00 & $0 / 6$ & 0.00 & 0.00 & $0 / 6$ & 0.00 & 0.00 \\
\hline $0.46 \%$ Ala & $1 / 6$ & $3 \cdot 27$ & 0.00 & $3 / 6$ & $3 \cdot 39^{\star *}$ & 0.05 & $0 / 6$ & 0.00 & 0.00 \\
\hline
\end{tabular}

Pro, mice fed with a normal gestation diet with $0.6 \%$ proline supplementation; Ala, mice fed with a normal gestation diet with $0.46 \%$ alanine supplementation, as the isonitrogenous control.

** Mean value was significantly different with respect to the proline group $(P<0.01)$

† Six mice from the Pro group and six mice from the Ala group were used for PCV2 virus load analysis. The detection rate is shown as number of positive mice/number of tested mice. The PCV2 load is shown as mean PCV2 $\log _{10}$ genomic copies per ml (and/or per g).

PCV2-infected pregnant mice. However, a numerically higher abortion rate was observed for the control compared with proline-supplemented mice, thus suggesting a need for further research with a larger sample size to adequately examine any potential role that dietary supplemental proline might have on abortion rates in PCV2-infected mice. However, the serum CRP level in the proline group is significantly higher than that in the control. CRP plays a role in host defence against bacterial pathogens, protection from lethal bacterial infection and endotoxaemia, the activation of complement, opsonisation and induction of phagocytosis ${ }^{(27-30)}$. Thus, this interesting observation indicates that proline supplementation confers a beneficial role in PCV2 infection. Another finding that dietary supplementation with proline significantly decreases both the PCV2 virus load and microscopic lesions in tissues also supports this conclusion. Collectively, these compelling results suggest that dietary supplementation with proline confers a significant positive effect in PCV2-infected pregnant mice.

PCV2 infection has been associated with lymphocyte depletion, interference with antigen presentation, apoptosis
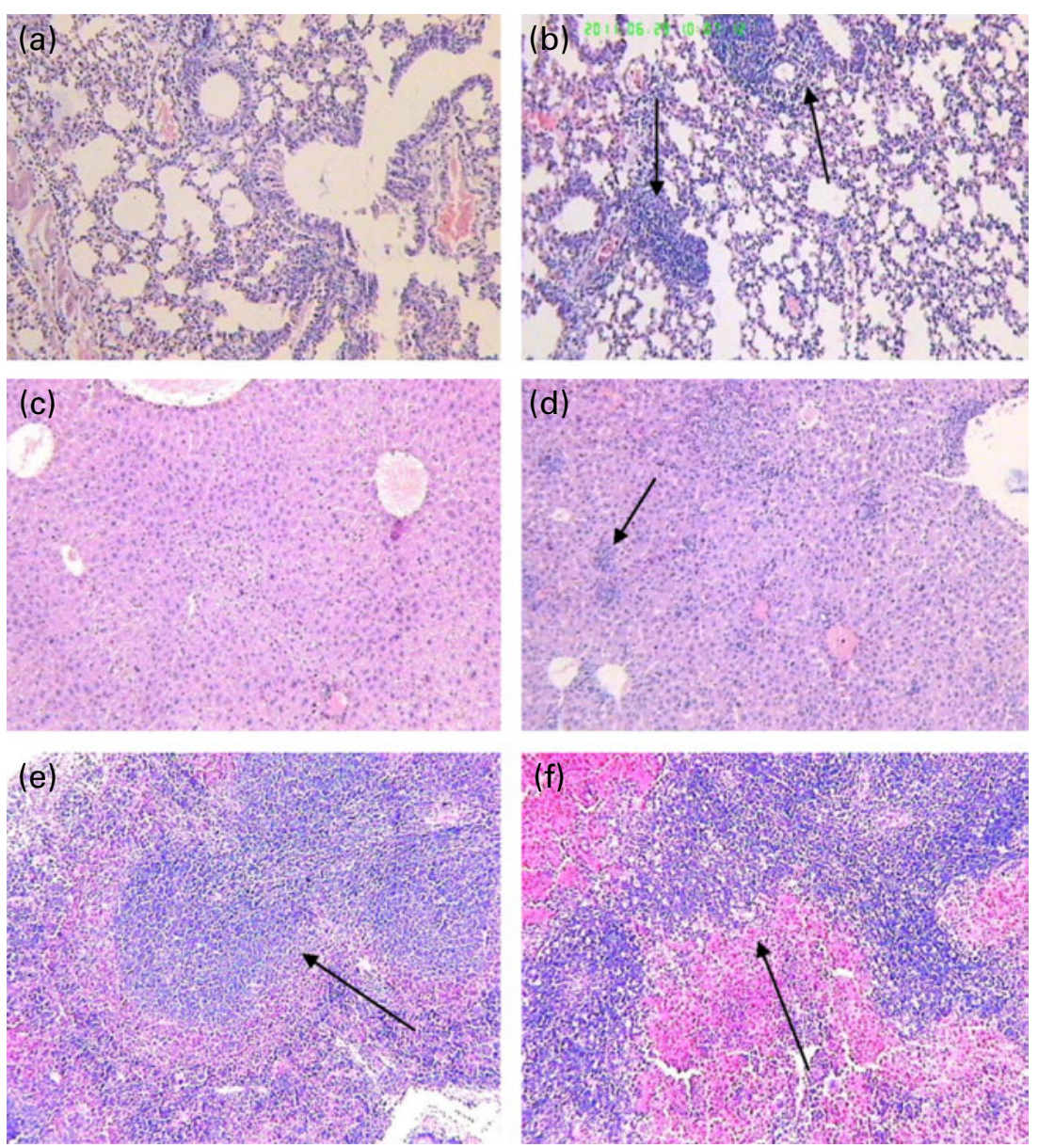

Fig. 1. Histopathological findings in the lung, liver and spleen $(\times 100)$. Mild interstitial pneumonia was evident in the lungs in the proline group (a) compared with the control group (b). The proline group (c) showed less lymphohistiocytic inflammation in the liver than the alanine control group (d). Additionally, the proline group showed less severe lymphoid depletion (e) in the spleen compared with the control group (f). (A colour version of this figure can be found online at http:// www.journals.cambridge.org/bjn) 
Table 7. Microscopic lesion scores for the tissue samples in porcine circovirus type 2 (PCV2)-infected pregnant and non-pregnant mice*

(Mean values with their standard errors)

\begin{tabular}{|c|c|c|c|c|c|}
\hline \multirow[b]{2}{*}{ Catalogues } & \multicolumn{2}{|c|}{ Pro } & \multicolumn{2}{|c|}{ Ala } & \multirow[b]{2}{*}{$P$} \\
\hline & Mean & SEM & Mean & SEM & \\
\hline \multicolumn{6}{|c|}{ PCV2-infected pregnant mice } \\
\hline Lung & 1.25 & 0.25 & $2 \cdot 35$ & 0.32 & 0.03 \\
\hline Liver & 0.25 & 0.25 & 1.50 & 0.29 & 0.01 \\
\hline Spleen & 1.50 & 0.28 & $2 \cdot 75$ & 0.25 & 0.01 \\
\hline \multicolumn{6}{|c|}{ PCV2-infected non-pregnant mice } \\
\hline Lung & 1.75 & 0.48 & 3.50 & 0.65 & 0.072 \\
\hline Liver & 0.50 & 0.29 & $2 \cdot 00$ & 0.41 & 0.024 \\
\hline Spleen & 0.75 & 0.25 & $2 \cdot 50$ & 0.26 & 0.004 \\
\hline
\end{tabular}

of monocyte/macrophage lineage cells and other antigenpresenting cells, and inhibition of the activity of natural interferon-producing cells ${ }^{(31-33)}$. Thus, PCV2 infection has been referred to as an immunosuppressant disease. In the present PCV2-infected non-pregnant mice, dietary supplementation with proline significantly increased leucocytes, lymphocytes and neutrophilic granulocytes in the blood. TNF- $\alpha$, which is secreted by both macrophages and monocytes, is an important member of the TNF family that plays a key role in immune regulation, and enhances lymphoid development, cell proliferation, differentiation, activation and death ${ }^{(34,35)}$. The serum TNF- $\alpha$ level in the proline group is much higher than that in the control alanine group. Moreover, we also found that interstitial pneumonia in the lung, lymphohistiocytic inflammation in the liver and lymphoid depletion in the spleen are more severe in the alanine group than in the proline group. Furthermore, dietary supplementation with proline decreased the PCV2 virus load in the lung. Taken together, these findings suggest that supplementation with proline also had a beneficial effect in PCV2-infected non-pregnant mice.

Similar to arginine and glutamine, proline plays an important role in immune responses. Duval et al. ${ }^{(36)}$ reported that proline plays a role in protecting lymphocytes from apoptosis, stimulating cell growth and promoting antibody production. Consistently, other studies have also shown that proline is crucial for wound healing and injury recovery mediated by cells of the immune system. Studies have found that proline plays an important role in multiple biochemical and physiological processes in human subjects and animals as a signalling molecule, a sensor of cellular energy status and a source of pyrroline-5-carboxylate and superoxide anion ${ }^{(37-39)}$. Proline also participates in cell differentiation, as well as conceptus growth and development ${ }^{(18)}$. Furthermore, proline is a major nitrogenous substrate for the synthesis of polyamines in the small intestine and placenta, which expands its role in fetal and neonatal nutrition ${ }^{(18,40,41)}$. Finally, proline can scavenge free radicals, and thus has vital antioxidant properties ${ }^{(42)}$. Consistent with these findings, another promising study has found that proline plays a role in cell growth and function by regulating the mammalian target of rapamycin activation pathway ${ }^{(43)}$.
In addition to proline itself, proline oxidase also plays a vital role in immune function. For example, Ha et al. ${ }^{(44)}$ reported that immune function in the gut is impaired because of a deficiency of intestinal proline oxidase, and thus suggested that proline oxidase may play an important role in immunity. $\mathrm{H}_{2} \mathrm{O}_{2}$, a major product of proline oxidation, is a signalling molecule and a cytotoxic agent towards pathogenic bacteria $^{(45)}$. Wu et al. ${ }^{(41,46)}$ proposed that a high activity of proline oxidase in the porcine placenta and the small intestine of piglets may play a crucial role in protecting these organs from infection during the critical periods of fetal and neonatal development. Sun et $a l^{(47)}$ indicated that proline oxidase is present in milk and may aid in protecting the neonatal intestine from bacterial and viral challenge ${ }^{(48)}$.

In conclusion, dietary supplementation with proline had no effect on abortion rate in pregnant mice infected with PCV2. However, a numerically lower abortion rate was observed for mice fed the proline-supplemented diet compared with the control. Feeding the proline-supplemented diet showed beneficial effects in pregnant and non-pregnant mice in terms of improved blood parameters and cytokine profile, and decreased tissue lesions and the PCV2 virus load in tissues. These benefits and the observed numerical difference in abortion rate warrant further research with sufficient observations to better substantiate any role that proline supplementation might have on abortion rates in PCV2-infected mice, and to elucidate the underlying mechanisms.

\section{Acknowledgements}

The present study was jointly supported by the National Basic Research Program of China (2012CB124704), the National Natural Science Foundation of China (no. 31110103909, 30901040 , 30928018 and 31101729) and the National Scientific and Technology Support Project (2011BAD26B002-5). Y. Y. and W. R. were in charge of the whole trial. W. R., R. H., Y. L. and X. Y. conducted the animal experiment and wrote the manuscript. M. W., W. L. and T. L. assisted with the animal trial and chemical analyses. The authors have no conflicts of interest to declare. 


\section{References}

1. Allan GM, McNeilly F, Kennedy S, et al. (1998) Isolation of porcine circovirus-like viruses from pigs with a wasting disease in the USA and Europe. J Vet Diagn Invest 10, 3-10.

2. Ren WK, Yu R, Liu G, et al. (2013) DNA vaccine encoding the major virulence factors of Shiga toxin type 2e (Stx2e)expressing Escherichia coli induces protection in mice. Vaccine 31, 367-372.

3. Segales J, Allan GM \& Domingo M (2005) Porcine circovirus diseases. Anim Health Res Rev 6, 119-142.

4. Opriessnig T, Meng XJ \& Halbur PG (2007) Porcine circovirus type 2 associated disease: update on current terminology, clinical manifestations, pathogenesis, diagnosis, and intervention strategies. J Vet Diagn Invest 19, 591-615.

5. Stevenson GW, Kiupel M, Mittal SK, et al. (2001) Tissue distribution and genetic typing of porcine circoviruses in pigs with naturally occurring congenital tremors. J Vet Diagn Invest 13, 57-62.

6. Jung BG, Toan NT, Cho SJ, et al. (2010) Dietary aluminosilicate supplement enhances immune activity in mice and reinforces clearance of porcine circovirus type 2 in experimentally infected pigs. Vet Microbiol 143, 117-125.

7. Monroe S \& Polk R (2000) Antimicrobial use and bacterial resistance. Curr Opin Microbiol 3, 496-501.

8. Ren W, Luo W, Wu M, et al. (2011) Dietary L-glutamine supplementation improves pregnancy outcome in mice infected with type-2 porcine circovirus. Amino Acids (Epublication ahead of print version 16 November 2011).

9. Ren W, Yin Y, Liu G, et al. (2012) Effect of dietary arginine supplementation on reproductive performance of mice with porcine circovirus type 2 infection. Amino Acids $\mathbf{4 2}$, 2089-2094.

10. Ren W, Li Y, Yu X, et al. (2013) Glutamine modifies immune responses of mice infected with porcine circovirus type 2. $\mathrm{Br}$ J Nutr 110, 1053-1060.

11. Liu XD, Wu X, Yin YL, et al. (2011) Effects of dietary L-arginine or $\mathrm{N}$-carbamylglutamate supplementation during late gestation of sows on the miR-15b/16, miR-221/222, VEGFA and eNOS expression in umbilical vein. Amino Acids 42, 2111-2119.

12. Kong XF, Yin YL \& Wu GY (2012) Arginine stimulates the mTOR signaling pathway and protein synthesis in porcine trophectoderm cells. J Nutr Biochem 23, 1178-1183.

13. Li P, Yin YL, Li D, et al. (2007) Amino acids and immune function. Br J Nutr 98, 237-252.

14. Hu CA, Phang JM \& Valle D (2008) Proline metabolism in health and disease. Preface. Amino Acids 35, 651-652.

15. Wu G (2009) Amino acids: metabolism, functions, and nutrition. Amino Acids 37, 1-17.

16. Tan Bie, Yin YL, Liu ZQ, et al. (2009) Dietary L-arginine supplementation increases muscle gain and reduces body fat mass in growing-finishing pigs. Amino Acids 37, 169-175.

17. Wu G, Bazer FW \& Tou W (1995) Developmental changes of free amino acid concentrations in fetal fluids of pigs. J Nutr 125, 2859-2868.

18. Wu G, Bazer FW, Datta S, et al. (2008) Proline metabolism in the conceptus: implications for fetal growth and development. Amino Acids 35, 691-702.

19. Kwon H, Spencer TE, Bazer FW, et al. (2003) Developmental changes of amino acids in ovine fetal fluids. Biol Reprod $\mathbf{6 8}$, 1813-1820.

20. Yao K, Yin Y, Li X, et al. (2012) $\alpha$-Ketoglutarate inhibits glutamine degradation and enhances protein synthesis in intestinal porcine epithelial cells. Amino Acids 42, 2491-2500.
21. Yin FG, Zhang ZZ, Huang J, et al. (2010) Digestion rate of dietary starch affects systemic circulation of amino acids in weaned pigs. Br J Nutr 103, 1404-1412.

22. Opriessnig T, Thacker EL, Yu S, et al. (2004) Experimental reproduction of postweaning multisystemic wasting syndrome in pigs by dual infection with Mycoplasma byopneumoniae and porcine circovirus type 2. Vet Pathol 41, 624-640.

23. Opriessnig T, Patterson AR, Meng XJ, et al. (2009) Porcine circovirus type 2 in muscle and bone marrow is infectious and transmissible to naive pigs by oral consumption. Vet Microbiol 133, 54-64.

24. Elango R, Ball RO \& Pencharz PB (2009) Amino acid requirements in humans: with a special emphasis on the metabolic availability of amino acids. Amino Acids 37, 19-27.

25. Mateusen B, Sanchez RE, Van Soom A, et al. (2004) Susceptibility of pig embryos to porcine circovirus type 2 infection. Theriogenology 61, 91-101.

26. Mateusen B, Maes DG, Van Soom A, et al. (2007) Effect of a porcine circovirus type 2 infection on embryos during early pregnancy. Theriogenology 68, 896-901.

27. Szalai AJ, Briles DE \& Volanakis JE (1995) Human C-reactive protein is protective against fatal Streptococcus pneumoniae infection in transgenic mice. J Immunol $\mathbf{1 5 5}$, $2557-2563$.

28. Szalai AJ, VanCott JL, McGhee JR, et al. (2000) Human C-reactive protein is protective against fatal Salmonella enterica serovar typhimurium infection in transgenic mice. Infect Immun 68, 5652-5656.

29. Volanakis JE (2001) Human C-reactive protein: expression, structure, and function. Mol Immunol 38, 189-197.

30. Szalai AJ (2002) The biological functions of C-reactive protein. Vascul Pharmacol 39, 105-107.

31. Kennedy S, Moffett D, McNeilly F, et al. (2000) Reproduction of lesions of postweaning multisystemic wasting syndrome by infection of conventional pigs with porcine circovirus type 2 alone or in combination with porcine parvovirus. J Comp Pathol 122, 9-24.

32. Vincent IE, Carrasco CP, Guzylack-Piriou L, et al. (2005) Subset-dependent modulation of dendritic cell activity by circovirus type 2. Immunology 115, 388-398.

33. Vincent IE, Balmelli C, Meehan B, et al. (2007) Silencing of natural interferon producing cell activation by porcine circovirus type 2 DNA. Immunology 120, 47-56.

34. Smyth MJ \& Johnstone RW (2000) Role of TNF in lymphocyte-mediated cytotoxicity. Microsc Res Tech 50, 196-208.

35. Ch'en PF, Xu XG, Liu XS, et al. (2005) Characterisation of monoclonal antibodies to the TNF and TNF receptor families. Cell Immunol 236, 78-85.

36. Duval D, Demangel C, Munier-Jolain K, et al. (1991) Factors controlling cell proliferation and antibody production in mouse hybridoma cells: I. Influence of the amino acid supply. Biotechnol Bioeng 38, 561-570.

37. Phang JM, Donald SP, Pandhare J, et al. (2008) The metabolism of proline, a stress substrate, modulates carcinogenic pathways. Amino Acids 35, 681-690.

38. Phang JM, Pandhare J \& Liu Y (2008) The metabolism of proline as microenvironmental stress substrate. J Nutr 138, 2008S-2015S

39. Phang JM, Liu W \& Zabirnyk O (2010) Proline metabolism and microenvironmental stress. Annu Rev Nutr 30, 441-463.

40. Wu G, Flynn NE \& Knabe DA (2000) Enhanced intestinal synthesis of polyamines from proline in cortisol-treated piglets. Am J Physiol Endocrinol Metab 279, E395-E402. 
41. Wu G, Bazer FW, Hu J, et al. (2005) Polyamine synthesis from proline in the developing porcine placenta. Biol Reprod 72, 842-850.

42. Kaul S, Sharma SS \& Mehta IK (2008) Free radical scavenging potential of L-proline: evidence from in vitro assays. Amino Acids 34, 315-320.

43. van Meijl LE, Popeijus HE \& Mensink RP (2010) Amino acids stimulate Akt phosphorylation, and reduce IL- 8 production and NF-kappaB activity in HepG2 liver cells. Mol Nutr Food Res 54, 1568-1573.

44. Ha EM, Oh CT, Bae YS, et al. (2005) A direct role for dual oxidase in Drosophila gut immunity. Science 310, 847-850.
45. Shi W, Meininger CJ, Haynes TE, et al. (2004) Regulation of tetrahydrobiopterin synthesis and bioavailability in endothelial cells. Cell Biochem Biophys 41, 415-434.

46. Wu G (1997) Synthesis of citrulline and arginine from proline in enterocytes of postnatal pigs. Am J Physiol 272, G1382-G1390.

47. Sun Y, Nonobe E, Kobayashi Y, et al. (2002) Characterization and expression of L-amino acid oxidase of mouse milk. J Biol Chem 277, 19080-19086.

48. Field CJ (2005) The immunological components of human milk and their effect on immune development in infants. $J$ Nutr 135, 1-4. 